\title{
RESEARCH ARTICLE \\ Correlation between the level of knowledge of drug managers and drug management in several primary health centres in Malang regency
}

\author{
Ayuk Lawuningtyas Hariadini, Nur Ishmah, Hananditia Rachma Pramestutie \\ Pharmacy Department, Faculty of Medicine, Universitas Brawijaya, Indonesia
}

\author{
Keywords \\ Drug management \\ Level of knowledge \\ Pharmacist \\ Pharmacy technician \\ Primary health centre

\section{Correspondence} \\ Ayuk Lawuningtyas Hariadini \\ Pharmacy department \\ Faculty of Medicine \\ Universitas Brawijaya \\ Indonesia \\ ayukhariadini@ub.ac.id
}

\begin{abstract}
Background: Drug management is one of the primary health centre management activities that aims to ensure the continuity and affordability of pharmaceutical preparations. Aim: This study aims to determine the relationship between the level of knowledge of drug managers and drug management in several primary health centres of Malang regency. Method: The study was observational analytic using questionnaire instruments to analyse the level of knowledge of drug managers and three checklists to analyse drug management through three indicators of drug management: (1) conformity of stock to the national formulary, (2) conformity of stock to the disease patterns, and (3) the percentage of expired drugs. Result: There was no significant relationship between the level of knowledge and the first $(p=0.842)$, second $(p=0.236)$, and the third indicator $(p=0.361)$. Conclusion: Not all drug lists in the national formulary are required by each primary health centre. The inventory is adjusted to the consumption and epidemiology.
\end{abstract}

\section{Introduction}

Pharmaceutical service activities at primary health centres are divided into two aspects, i.e. drug management and pharmaceutical clinical services (Minister of Health, 2016). This study focused on the drug management aspect. According to the Ministry of Health $(\mathrm{MoH})$ regulation number $74 / 2016$, one of the objectives of drug management is to carry out service quality control, which affects the pharmaceutical clinical service process related to patient therapy. Efficient drug management relies entirely on robust healthcare systems. Sufficient staffs, viability fund, broad information systems, and synchronized healthcare teams and institutions are key components to secure the availability and accessibility of essential medicines (World Health Organization, 2015). Drug management consists of nine aspects, i.e. planning, procurement, receiving, storing, distributing, destruction and withdrawal, controlling, administration, and monitoring and evaluating processes. At primary health centres, it is carried out by pharmaceutical staff (Minister of Health, 2016). It can be measured through ten indicators based on the Indonesian $\mathrm{MoH}$ and Japan International Cooperation Agency (JICA), namely the suitability of drug availability with National List of Essential Medicines (NLEM) or national formulary, compatibility of drug availability with disease patterns, percentage and value of expired or damaged drugs, level of drug availability, the accuracy of drug demand, the average weight percentage of inventory variations, the average percentage of time vacancies of drugs, the percentage of drugs that are not prescribed, the accuracy of drug distribution, and the percentage of generic drug prescription writing (Minister of Health \& Agency, 2010). In this study, researchers focused on three indicators of drug management: suitability of drug availability with the national formulary (indicator 1), 
suitability of drug availability with disease patterns (indicator 2), and expired or damaged drugs (indicator $3)$. These three indicators are likely to represent and fulfill the nine aspects of drug management, and variations between Primary Health Centres (Puskesmas) tend to be minimal.

Pharmacy staff includes pharmacists and technicians who do pharmaceutical work. Pharmacy staff is the party directly related to the process of delivering drug information to patients. According to $\mathrm{MoH}$ regulation number 74/2016 Chapter 4 (Pharmaceutical Resources in Primary Health Center), at least one pharmacist acts as the person in charge and can be assisted by pharmacy technicians as needed (Minister of Health, 2016). However, research in 2011 reported that in all Indonesian primary health centres, only $17.5 \%$ had pharmacists, and $32.2 \%$ had no pharmaceutical staff at all (Herman et al., 2011). Additionally, data from 2016 shows that out of 33 districts comprising 39 primary health centres in Malang Regency, 15 primary health centres have pharmaceutical staff (pharmacists and pharmacy technicians), and 24 primary health centres do not have pharmaceutical personnel (Ministry of Health, 2017). In this context, the urgency of the availability of pharmaceutical personnel, especially pharmacists, in implementing drug management at primary health centres is perceived.

One of the factors that can influence drug management is the level of knowledge of drug administrators. It is established that all pharmaceutical staff needs to improve knowledge, skills, and behaviour to increase their competence in pharmaceutical services at primary health centres (Minister of Health, 2016). Indeed, a study reported a positive relationship between the level of knowledge and drug management at Banyumas primary health centres (Aryani et al., 2016). Based on the urgency of availability of pharmaceutical staff and their level of knowledge, both of which affect drug management in primary health centres, it was deemed necessary to explore the relationship between the level of knowledge and drug management in several primary health centres in Malang Regency.

Therefore, this study aimed to evaluate the knowledge level of drug administrators related to drug management theory, measure the level of drug management through three indicators, and determine the relationship between the knowledge level of drug administrators and drug management in several primary health centres in Malang regency.

\section{Methods}

This analytic observational study used a cross-sectional approach, where the relationship between variables will be evaluated through the data obtained by direct observation. It was conducted at 12 primary health centres in Malang Regency from March to June 2019. The instruments used were a questionnaire to assess the knowledge level of drug administrators and three checklists to measure drug management at the primary health centres. First, drug administrators completed the questionnaire then they were interviewed as supporting data. Finally, the researchers filled out a checklist adjusted to the data from the primary health centres. This research has also fulfilled the ethical clearance of the Health Research Ethics Commission of the Faculty of Medicine, Universitas Brawijaya, number 84/EC/KEPK-S1-FARM/03/2019.

\section{Validity and reliability test}

The validity and reliability of the questionnaire were tested before starting the study. The test was carried out on 15 samples outside the research sample using SPSS and MS Excel. Respondents for the validity test were all pharmaceutical personnel from five health centres representing five sub-districts in the city of Malang.

\section{Sample}

Respondents in this study were all drug administrators, both with pharmaceutical and non-pharmaceutical educational backgrounds. The total sampling technique was used. The determination of primary health centre samples was carried out using the clustered random sampling method, and 12 primary health centres in Malang Regency were obtained, representing each district, i.e. north, west, south, and east of Malang Regency.

\section{Inclusion criteria}

Included were drug administrators willing to participate, complete the questionnaire, and provide information related to data. The inclusion criteria for primary health centres was to provide research permits and documentations or archives of the data required.

\section{Exclusion criteria}

Exclusion criteria consisted of staff outside the pharmacy room. Primary health centres that were excluded were those outside Malang regency and those with poor administrative processes related to the availability of data.

\section{Data analysis}

This study involved two types of data, namely questionnaire data and data from the three checklists. 
The questionnaire included 20 dichotomised (true or false) questions scored 1 or 0 , put into percentages, and categorised into high, medium, and low (Arikunto, 2013). Moreover, three checklists for three indicators of drug management (suitability of drug availability with national formulary, suitability of drug availability with disease patterns, and percentage of expired drugs) were filled according to usage reports and drug request sheets (LPLPO) data, top 10 disease patterns in February 2019, expired drug list, and stock recording. The percentage of the three checklists calculated based on the predetermined formula (Minister of Health \& Agency, 2010) were categorised into three categories: good, moderate, and poor (Azwar, 2012). After that, the normality test was carried out using the Shapiro Wilk method, followed by the correlation test using the Pearson Correlation method, each of which was analyzed using SPSS and MS Excel. From the correlation results obtained, a $p<0.05$ indicated a significant relationship between the knowledge level of drug administrators and drug management at the health center, whereas a $p>0.05$ indicated no significant relationship between the two variables (Arikunto, 2013).

\section{Results}

This study enrolled was 15 drug administrators from 12 health centres in Malang regency (Table I).

Table I: Characteristics of respondents

\begin{tabular}{|c|c|c|c|}
\hline Parameter & Category & Number & $\begin{array}{c}\text { Percentage } \\
\text { (\%) }\end{array}$ \\
\hline \multirow[t]{5}{*}{ Age } & $17-25$ & 1 & 7.14 \\
\hline & $26-35$ & 4 & 28.57 \\
\hline & $36-45$ & 6 & 42.86 \\
\hline & $46-55$ & 2 & 14.29 \\
\hline & $55-65$ & 1 & 7.14 \\
\hline \multirow[t]{4}{*}{$\begin{array}{l}\text { Educational } \\
\text { background }\end{array}$} & $\begin{array}{l}\text { Pharmacy high } \\
\text { school }\end{array}$ & 4 & 28.57 \\
\hline & $\begin{array}{l}\text { Pharmacy } \\
\text { diploma }\end{array}$ & 7 & 50 \\
\hline & $\begin{array}{l}\text { Bachelor of } \\
\text { pharmacy }\end{array}$ & 1 & 7.14 \\
\hline & Pharmacist & 2 & 14.29 \\
\hline \multirow{4}{*}{$\begin{array}{l}\text { Working } \\
\text { experience }\end{array}$} & $<12$ months & 1 & 7.14 \\
\hline & $1-5$ years & 1 & 7.14 \\
\hline & $5-10$ years & 6 & 42.86 \\
\hline & $>10$ years & 6 & 42.86 \\
\hline
\end{tabular}

The analysis of the level of knowledge was carried out using a questionnaire with the percentages of correct answers categorised into low $(\leq 55 \%)$, moderate (56$75 \%)$, and high (76-100\%) (Arikunto, 2013). The average level of knowledge of drug administrators from 14 respondents in 12 primary health centres was $88.21 \%$, indicating that most respondents were in the higher category. The 20-item questionnaire covered nine aspects of drug management, i.e., planning, procurement, receiving, storing, distributing, destruction and withdrawal, controlling, administration, and monitoring and evaluating processes. A summary of the results is presented in Table II.

Table II: Categorisation of the knowledge level

\begin{tabular}{lcc}
\hline Category & \multicolumn{2}{c}{ Pharmacy room manager } \\
& $\begin{array}{c}\text { Pharmacist } \\
(\mathbf{n}=\mathbf{2})(\%)\end{array}$ & $\begin{array}{c}\text { Non pharmacist } \\
(\mathbf{n}=\mathbf{1 2})(\%)\end{array}$ \\
\hline High & $2(100)$ & $11(91,67)$ \\
\hline Moderate & 0 & $1(7,14)$ \\
Low & 0 & 0 \\
\hline
\end{tabular}

\section{Drug management}

Drug management was measured through three indicators, i.e. suitability of drug availability with national formulary, suitability of drug availability with disease patterns, and percentage of expired drugs.

Drug management based on suitability of drug availability with a national formulary

The results of the categorisation of Indicator 1 presented in Table III were based on the categorization calculation of Saifuddin Azwar (Azwar, 2012).

Table III: Drug management profile based on indicator 1

\begin{tabular}{cc}
\hline Category & $\begin{array}{c}\text { Primary health centre } \\
(\mathbf{n}=\mathbf{1 2})(\%)\end{array}$ \\
\hline Good & $3(25)$ \\
\hline Fair & $6(50)$ \\
Poor & $3(25)$ \\
\hline
\end{tabular}

Drug management in this indicator was measured using checklist 1 in the form of a list of drugs in national formulary and the percentage of the number of drugs available at the primary health centres in February 2019. The percentage obtained was categorised into three categories: good if the score was $\geq($ mean +1.0$)$, fair if (mean - 1.0) $\leq$ score $<($ mean +1.0$)$, and poor if the score was $<$ (mean - 1.0) (Azwar, 2012). 
Drug management based on suitability of drug availability with disease patterns

The results of the categorization of Indicator 2 presented in Table IV were based on the categorisation calculation of Saifuddin Azwar (Azwar, 2012).

Table IV: Drug management profile based on indicator 2

\begin{tabular}{cc} 
Category & $\begin{array}{c}\text { Primary health centre } \\
(\mathbf{n}=\mathbf{1 2})(\%)\end{array}$ \\
\hline Good & $3(25)$ \\
\hline Fair & $5(41.67)$ \\
\hline Poor & $4(33.33)$ \\
\hline
\end{tabular}

The disease patterns were limited to only the top 10 disease patterns in the primary health centres in February 2019 and analysed using checklist 2, and the percentage of the number of drugs available for treatment was calculated against the top 10 disease patterns to the number of drugs used. The availability for treatment of the top 10 disease patterns was according to the national formulary.

Drug management based on expired or damaged drugs

The results of the categorization of Indicator 3 presented in Table $V$ were based on the categorisation calculation of Saifuddin Azwar (Azwar, 2012).

Table V: Drug management profile based on indicator 3

\begin{tabular}{cc}
\hline Category & $\begin{array}{c}\text { Primary health centre } \\
(\mathbf{n}=\mathbf{1 2}) \mathbf{( \% )}\end{array}$ \\
\hline Good & $4(33.33)$ \\
\hline Fair & $2(16.67)$ \\
\hline Poor & $6(50)$ \\
\hline
\end{tabular}

Drug management profile based on expired or damaged drugs was analysed using checklist 3, which was a list of expired or damaged drugs. The results were calculated through the percentage between the number of expired or damaged drugs and the number of drugs available at the primary health centres. Indicator 3 was carried out on expired or damaged drug data and the stock recorded in 2018. The percentage obtained was categorised into three categories: good if the score was < (mean - 1.0), fair if (mean - 1.0) $\leq$ score $<($ mean +1.0$)$, and poor if the score was $\geq($ mean +1.0$)$ (Azwar, 2012).

\section{Correlation analysis}

Table VI shows the results of the correlation analysis between the levels of knowledge of each indicator in drug management at 12 primary health centres.

Table VI: Correlation analysis

\begin{tabular}{lccc}
\hline Variable & $\begin{array}{c}\text { Pearson } \\
\text { correlation }\end{array}$ & Significance & Information \\
\hline Indicator 1 & 0.065 & 0.842 & Not significant \\
\hline Indicator 2 & 0.370 & 0.236 & Not significant \\
\hline Indicator 3 & 0.289 & 0.361 & Not significant \\
\hline
\end{tabular}

A correlation test was carried out on each indicator, and three correlations were obtained. The value of correlation 1 between the level of knowledge and suitability of drug availability with the national formulary was 0.065 , with a significance of 0.842 , corresponding to a very weak and not significant correlation (in the range of 0.001-0.199) (Jacob Benesty et al., 2009; Arikunto, 2013).

The value of correlation 2 between the level of knowledge and suitability of drug availability with disease patterns was 0.370 , with a significance of 0.236 , indicating weak and not significant correlation (in the range of 0.20-0.399) (Jacob Benesty et al., 2009; Arikunto, 2013).

The value of correlation 3 between the level of knowledge and percentage of expired or damaged drugs was 0.289 , with a significance of 0.361 , showing weak and not significant correlation (in the range of 0.20-0.399) (Jacob Benesty et al., 2009; Arikunto, 2013).

The results of the 12 health centres show that knowledge levels do not have a significant effect on drug management, indicating that several other underlying factors could affect knowledge and drug management.

\section{Discussion}

The majority of respondents were 36-45 years old, were pharmacists, and worked for 5-10 years and more than ten years (Table I). According to Notoatmodjo (2007), age, education, and experience could affect the level of knowledge. Older age will further enhance one's experience in various domains and is directly proportional to the level of knowledge. However, age does not always describe a person's level of knowledge. Previous research reported no relationship between age and drug management among drug administrators 
(Malahayati, 2016). Furthermore, educational background and working period are directly proportional to the level of knowledge. The higher the education and the longer the working period, the higher the level of knowledge (Katajavuori et al., 2009).

Theoretically, the level of knowledge can be influenced by the characteristics of the respondents, such as age, educational background, working period, where the higher the age and working experience, the higher the level of knowledge. As for education, it is related to the acceptance of information, where higher education can increase knowledge (Triana et al., 2014). In this study, age, educational background, and working period did not have a significant effect on the level of knowledge. The values obtained tended to be the same between one administrator and another, although they had different characteristics, indicating other factors can affect the level of knowledge of the administrators. The literature also states that the environment can also affect the level of knowledge related to a reciprocal interaction, which will then be responded to as knowledge by every individual (Notoatmodjo, 2007). Additionally, knowledge can also be influenced by the interests and activities of administrators. The higher a person's interest in a topic related to independent information retrieval, the more knowledgeable the person will be. The activity itself is known to have a significant relationship with the level of knowledge with a value of $p=0.015$ (Harisman \& Nuryani, 2012). However, in this study, no further analysis was carried out regarding environmental factors, interests, or activities of drug officers.

Based on the interview results, the high level of knowledge of drug officers was influenced by the socialization provided by the Malang Regency Health Office (DHO), notification of the latest information, and periodic evaluation of drug management in each primary health centre. The provision of this information can further increase the knowledge of officers manifested by the high percentage score of the level of knowledge obtained. The difference in the scores obtained could be due to ambiguities in the questionnaire related to the disparity between existing theories and actual field conditions.

Table III (Indicator 1 ) shows that three primary health centres (25\%) were categorised as good (1 primary health centre with a pharmacist and 2 with pharmacy technicians), 6 (50\%) were in the fair category (1 primary health centre with a pharmacist and 5 with pharmacy technicians), and 3 (25\%) were in the poor category (pharmacy technicians only). It is noteworthy that the standard value of this indicator is $100 \%$ (Minister of Health \& Agency, 2010), and the percentage range obtained from 12 primary health centres is $70.80 \%-80.56 \%$, with an average of $76.66 \%$, indicating that the 12 primary health centres have not reached the set standard value. Several factors can influence, such as the basis for consideration of planning needs based on consumption patterns and disease patterns at the primary health centres, where consumption patterns will also be influenced by patterns of drug demand from prescribers in the implementation of primary health centre clinical services. Also, the demand from the primary health centre to the district pharmacy warehouse (GFK) sometimes includes drugs that are not in accordance with the national formulary but are needed by the primary health centres for services. There are also several conditions where the demand from primary health centres is not yet available at GFK, which can be due to various factors; thus, the percentage of suitability obtained will decrease. However, in this study, the researchers did not conduct further research on either the GFK or the Malang DHO.

Table IV (Indicator 2 ) shows that, out of the 12 primary health centres, $3(25 \%)$ were categorised as good (1 primary health centre with a pharmacist and 2 with pharmacy technicians), 5 (41.67\%) belonged to the fair category ( 1 primary health centre with a pharmacist and 4 with pharmacy technicians), and 4 (33.33\%) were in the poor category (pharmacy technicians). The standard value for Indicator 2 is $100 \%$ (Minister of Health \& Agency, 2010), and the percentage of the 12 primary health centres ranged between $68.75 \%$ $90.12 \%$, with an average of $79.44 \%$, revealing that all health centres have not reached the standards set. This result can be influenced by several aspects, including the pattern of drug consumption and drug availability at the GFK. However, regarding Indicator 2, the researchers only focused on the top 10 disease patterns, as it could not describe all cases of diseases in the primary health centres. The results of this study were in contrast with previous findings in southern Papua, showing the average suitability of drug availability with disease patterns in the district of $170.87 \%$. This result indicates that all districts provide more types of drugs than the existing disease patterns in their regions, resulting in a waste of drug procurement budgets (Waluyo et al., 2014).

Table V (Indicator 3 ) shows that out of the 12 primary health centres, 4 (33.33\%) were categorized as good ( 2 primary health centres with pharmacists and 2 with pharmacy technicians), 2 (16.67\%) were in the fair category (pharmacy technicians), and 6 (50\%) belonged to the poor category (pharmacy technicians). The standard value for Indicator 3 is $0 \%$ (Minister of Health \& Agency, 2010), and the percentage of 12 primary health centres ranged between $0 \%-14.44 \%$, with an average of $7.22 \%$. Only one primary health centre had reached the standard value. The results obtained could 
be influenced by unpredictable changes in disease patterns, where demand was previously based on disease and consumption patterns. Some drugs that had been ordered were not used due to changes in disease patterns. Furthermore, in some conditions, changing prescribers can sometimes lead to the use of other drugs with the same indication. Hence, drugs often used by previous prescribers become unused by the replacing prescriber, thus being available and resulting in excessive supply from the GFK. These factors could lead to expired drugs. Poor compliance with the national guideline for drug disposition increases the risk of environmental contamination and the probability of consuming harmful pharmaceutical wastes by humans and animals, emphasising the need to develop drug management procedures for expired drugs to stop contaminations (Michael et al., 2019).

The results of the analysis and discussion show that the relationship between the level of knowledge and each indicator tended to be weak and not significant, as knowledge did not significantly affect drug management in the 12 primary health centres. The level of knowledge of 14 respondents was in the high category, with an average value of $88.21 \%$. Regarding drug management, the percentages of primary health centres categorized as good for Indicator 1, Indicator 2, and Indicator 3 were 25\%, 25\%, and $33.33 \%$, respectively.

\section{Conclusion}

The correlation between the level of knowledge and drug management based on three indicators (conformity of stock to the national formulary, conformity of stock to the disease patterns, and the percentage of expired drugs) tends to be weak and insignificant. Most pharmacy staff at primary health centres have good knowledge of drug management theory, but only a small proportion could achieve the drug management target. Therefore, it is necessary to solve the following problems: 1) making available the drugs needed by the primary health centre but not listed in national formulary, 2) meeting the need for drugs according to the most prevalent disease patterns, and 3) adding drugs, such as anti-tuberculosis, ferrous sulfate tablets, and zinc tablets, which were dropped from the government as they were too excessive.

\section{References}

Arikunto, S. (2013). Research procedure: a practice approach. Rineka Cipta
Aryani, A. F., Kusuma, A. M., \& Galistiani, G. F. (2016). Correlation between drugs manager knowledge level and their drugs management ability at public health. Jurnal manajemen dan pelayanan farmasi, 6(4), 303. https://doi.org/10.22146/jmpf.360

Azwar, S. (2012). Psychological scale compilation (2nd ed.). Pustaka Pelajar

Harisman, \& Nuryani, D. D. (2012). Factors affecting the activeness of integrated service post (Posyandu) cadres at Desa Mulang Maya Kecamatan Kotabumi Selatan Kabupaten Lampung Utara 2012. Jurnal Dunia Kesmas, 1(4), 196-203

Health, Minister of. (2016). Minister of Health (MoH) regulation number 74/2016 about pharmaceutical services standard at primary health center

Health, Minister of, \& Agency, J. I. C. (2010). Pharmaceutical management training material at the health center

Health, Ministry of. (2017). Basic data of primary health centers in East Java province December 2016 condition

Herman, M. J., Supardi, S., \& Yuniar, Y. (2011). Relationship of The Availability of Pharmacist with Characteristics of Primary Health Center and Pharmacy Practice in Health Center. Buletin Penelitian Sistem Kesehatan, 16, 88-98

Jacob Benesty, Chen, J., Huang, Y., \& Cohen, I. (2009). Pearson Correlation Coefficient. In Noise Reduction in Speech Processing (pp. 1-4). Springer, Berlin, Heidelberg. https://doi.org/https://doi.org/10.1007/978-3-642-002960_5

Katajavuori, N., Hakkarainen, K., Kuosa, T., Airaksinen, M., Hirvonen, J., \& Holm, Y. (2009). Curriculum reform in Finnish pharmacy education. American Journal of Pharmaceutical Education, 73(8), 1-7. https://doi.org/10.5688/aj7308151

Malahayati, N. (2016). Factors related to drug management by officers at the pharmacy installation at RSUD Dr Zubir Mahmud 2016

Michael, I., Ogbonna, B., Sunday, N., Anetoh, M., \& Matthew, O. (2019). Assessment of disposal practices of expired and unused medications among community pharmacies in Anambra State southeast Nigeria: A mixed study design. Journal of Pharmaceutical Policy and Practice, 12(1), 1-10. https://doi.org/10.1186/s40545-019-0174-1

Notoatmodjo, S. (2007). Health promotion and health sciences. Rineka Cipta

Triana, M., Suryawati, C., \& Sriyatmi, A. (2014). Evaluation on Drug Planning for Basic Health Services at Pharmaceutical Warehouses of Gunung Mas District, Central Kalimantan. Jurnal Manajemen Kesehatan Indonesia, 2(01), 44-51

Waluyo, Y., Athiyah, U., \& Nurul Rochmah, T. (2014). Analysis of factor influencing public drug management in district pharmacy installation (study in southern Papua area). Jurnal IImu Kefarmasian Indonesia, 13(1), 94-101

World Health Organization. (2015). Technical Consultation on Preventing and Managing Global Stock Outs of Medicines. WHO, December, 1-22. http://www.who.int/medicines/areas/access/Medicines _Shortages.pdf?ua=1 